\title{
Erratum to: The utility of lumbar spine trabecular bone score and femoral neck bone mineral density for identifying asymptomatic vertebral fractures in well-compensated type 2 diabetic patients
}

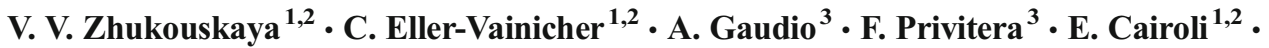 \\ F. M. Ulivieri ${ }^{4}$ S. Palmieri ${ }^{1,2}$ - V. Morelli ${ }^{1,2}$ - V. Grancini ${ }^{1,2}$ - E. Orsi ${ }^{1,2} \cdot$ B. Masserini ${ }^{1}$. \\ A. M. Spada ${ }^{1,2}$ - C. E. Fiore ${ }^{3}$ I. Chiodini ${ }^{1,2}$
}

Published online: 21 July 2015

(C) International Osteoporosis Foundation and National Osteoporosis Foundation 2015

Erratum to: Osteoporos Int

DOI 10.1007/s00198-015-3212-0

In the original publication the name of the second author, C. Eller-Vainicher, was rendered wrongly. The authors and publisher are pleased to correct this error here.

The online version of the original article can be found at http://dx.doi.org/ $10.1007 / \mathrm{s} 00198-015-3212-0$.

V. V. Zhukouskaya

volha.zhukouskaya@gmail.com

1 Units of Endocrinology and Metabolic Diseases, Fondazione IRCCS Cá Granda-Ospedale Maggiore Policlinico, Milan, Italy

2 Present address: Department of Clinical Sciences and Community Health, University of Milan, Padiglione Granelli, Francesco Sforza Street 35, 20122 Milan, Italy

3 Department of Internal Medicine, University of Catania, Catania, Italy

4 Units of Nuclear Medicine, Fondazione IRCCS Cá Granda-Ospedale Maggiore Policlinico, Milan, Italy 